\title{
The impact of community-delivered models of malaria control and elimination: a systematic review
}

Win Han Oo $0^{1,2^{*}} \mathbb{B}$, Lisa Gold' , Kerryn Moore ${ }^{2,3}$, Paul A. Agius $2,4,5$ and Freya J. I. Fowkes $2,3,4$

\begin{abstract}
Background: Community-delivered models have been widely used to reduce the burden of malaria. This review aimed to explore different community-delivered models and their relative effectiveness in terms of coverage and malaria-metric outcomes in order to inform the design and implementation of Community Health Worker (CHW) programmes for malaria control and elimination.
\end{abstract}

Methods: A systematic review of studies investigating the impact of community-delivered models on coverage and malaria-metric (parasitaemia and hyperparasitaemia, malaria case and mortality, anaemia, and fever) outcomes compared to non- community-delivered models was undertaken by searching in five databases of published papers and grey literature databases. Data were extracted from studies meeting inclusion and quality criteria (assessed using relevant tools for the study design) by two independent authors. Meta-analyses were performed where there was sufficient homogeneity in effect and stratified by community-delivered models to assess the impact of each model on coverage and malaria-metric outcomes.

Results: 28 studies were included from 7042 records identified. The majority of studies (25/28) were performed in high transmission settings in Africa and there was heterogeneity in the type of, and interventions delivered as part of the community-delivered models. Compared to non- community-delivered models, community-delivered models increased coverage of actual bed net usage (Relative Risk $(R R)=1.6495 \% \mathrm{Cl} 1.39,1.95$ ), intermittent preventive treatment in pregnancy $(\mathrm{RR}=1.3695 \% \mathrm{Cl} 1.29,1.44)$ and appropriate and timely treatment of febrile children, and improved malaria-metric outcomes such as malaria mortality $(R R=0.5895 \% \mathrm{Cl} 0.52,0.65)$. However, the considerable heterogeneity was found in the impact of community-delivered models in reducing, parasitaemia and hyperparasitaemia prevalence, anaemia incidence, fever prevalence and malaria caseload. Statistical comparisons of different community-delivered models were not undertaken due to the heterogeneity of the included studies in terms of method and interventions provided.

Conclusion: Overall, the community-delivered model is effective in improving the coverage of malaria interventions and reducing malaria-associated mortality. The heterogeneity of the community-delivered models and their impact on malaria-metric indices suggests that evidence for context-specific solutions is required. In particular, communitydelivered models for malaria elimination, integrated with services for other common primary health problems, are yet to be evaluated.

Keywords: Malaria, Community health worker, Community-delivered model, Coverage, Malaria-metric outcomes

\footnotetext{
${ }^{*}$ Correspondence: winhan.oo@burnet.edu.au

${ }^{2}$ Burnet Institute, 85 Commercial Rd, Melbourne, VIC 3004, Australia

Full list of author information is available at the end of the article
} 


\section{Background}

Malaria caused by Plasmodium spp. is an infectious disease transmitted by Anopheles mosquitoes. Despite a $18 \%$ decrease in malaria incidence rate since 2010 [1] and reinvigorated goals of malaria elimination, in the past few years the decline in the malaria burden has stalled and around half the global population is still at risk of malaria with around 219 million cases and 435,000 deaths in 2017 [1]. Recent reductions in malaria incidence has largely been attributed to the introduction of highly efficacious artemisinin-based combination therapy and high universal coverage of long-lasting insecticidal nets (LLIN), as well as testing (through increased availability and accessibility of rapid diagnostic tests) and targeted treatment of at-risk populations [2, 3].

A key challenge in malaria control is delivery of malaria interventions to the communities that need them most. One widely used model is a community-delivered model in which malaria interventions are delivered by community health workers (CHW). The World Health Organization defines that $\mathrm{CHW}$ should be members of the communities where they work, selected by, and answerable to, the communities, supported by the health system, but not necessarily a part of its organization, and should have shorter training than professional workers [4]. The use of CHW is attractive as they can be implemented with minimal training [5], they are readily available and are effective and cost-effective in resource-limited countries and several health areas [6-8].

Different community-delivered models for malaria control and elimination have been developed and implemented, namely the traditional $\mathrm{CHW}$ (tCHW) model, Integrated Community Case Management (iCCM), and Home Management of Malaria (HMM) according to the services provided and level of delegation of the interventions (Table 1). The tCHW model has been widely used since the 1980s across Africa and Asia to deliver malaria services. In the tCHW model, health authorities train the community-selected volunteers and equip them with tools such as malaria diagnostic tests, anti-malarial medicines, and communication tools for behaviour change communication for malaria prevention and control. The volunteers then provide malaria services for their community with the supervision and support of health staff. iCCM is a more recent strategy adopted in 2010 and has been used in some African countries, such as Nigeria and Uganda. The iCCM is an integrated model, intended for children under 5 years old, whereby malaria interventions are delivered along with the interventions for common life-threatening non-malaria diseases, typically pneumonia and diarrhoea. HMM has been implemented in many African countries including Uganda, Senegal, Nigeria, Ghana, Guinea, Ethiopia, Burkina Faso and Cameroon, and is characterized as deployment of malaria diagnosis, treatment and referral services up to the household level and in this model, the household member (usually the mothers or caregivers of under- 5 children) prescribes anti-malarial medicine to other household members or neighbours (usually the under- 5 children of own household or neighbours' households).

CHW will be essential in order to accelerate progress in reducing the burden of malaria and to achieve malaria elimination targets. As such, it is important to understand the utility and effectiveness of community-delivered models, which have varied across settings. Previous systematic reviews on community-delivered models, published between 2007 and 2014 [9-18], have been restricted to specific targeted population such as under-5 children $[9,10]$ or pregnant women $[11,18]$, interventions for malaria alone $[12-14,16,17]$ or geographical regions such as sub-Saharan Africa $[9,10,12,15,16]$ or low and middle income countries $[11,13]$. The aim of this systematic review was to provide holistic evidence for the different types of community-delivered models and their relative effectiveness in changing coverage (community utilization of quality malaria services) and malaria-metric indices (malaria disease burden and its consequences), compared to non- community-delivered models, in order to inform the design and implementation of $\mathrm{CHW}$ for malaria control and elimination.

\section{Methods}

A systematic review of published and grey literature of quantitative studies investigating community-delivered models for malaria only or malaria plus other diseases interventions to control or eliminate malaria was conducted. The terminology for community-delivered health care models varied across studies (Additional file 1) and is hereafter referred to as CHW. The protocol for this review was prospectively registered with PROSPERO (protocol number CRD42016052929) and adheres to the PRISMA [19] and MOOSE [20] guidelines for systematic reviews. The full protocol and data extraction tools can be found in Additional file 2 and is summarized below.

\section{Search strategy and selection criteria}

All interventional and observational studies conducted on intended study participants in malaria-endemic areas (defined by the Malaria Atlas Project [21]) that contain data describing the outcomes or processes involved in community-based delivery of any malaria or malaria plus other diseases interventions were included (Fig. 1).

PubMed, Embase, Cochrane Central Register of Controlled Trials, LILACS and African Medicus Index were searched with no restrictions on language (Additional file 3) up to and including 6th September 2018. Searches 
Table 1 Characteristics of the 28 included papers

\begin{tabular}{|c|c|c|c|c|c|c|}
\hline Author & Country & Malaria transmission & Design & Model & $\begin{array}{l}\text { Malaria }(M) \\
\text { or malaria } \\
\text { plus }(M+)\end{array}$ & $\begin{array}{l}\text { Malaria intervention } \\
\text { delivered }\end{array}$ \\
\hline Linn et al. [36] & Myanmar & Endemic $^{a}$ & Retrospective cohort & $\mathrm{tCHW}$ & M & $\begin{array}{l}\text { Parasitological } \\
\qquad \mathrm{dx}+\mathrm{Tx}+\text { referral }+\mathrm{BCC}\end{array}$ \\
\hline Alonso et al. [57] & Gambia & Holo-endemic ${ }^{a}$ & $\begin{array}{l}\text { Quasi-experiment with } \\
\text { control }\end{array}$ & $\mathrm{tCHW}$ & M & $\begin{array}{l}\text { ITN + parasitological } \\
\mathrm{dx}+\mathrm{Tx}+\text { referral }+\mathrm{BCC}\end{array}$ \\
\hline Delacollette et al. [40] & Zaire (Congo) & Meso-endemic ${ }^{a}$ & $\begin{array}{l}\text { Quasi-experiment with } \\
\text { control }\end{array}$ & $\mathrm{tCHW}$ & M & ITN + chemoprohylaxis \\
\hline Greenwood et al. [41] & Gambia & Seasonal ${ }^{\mathrm{a}}$ & $\begin{array}{l}\text { Quasi-experiment with } \\
\text { control }\end{array}$ & $\mathrm{tCHW}$ & M & IPTC \\
\hline Hamainza et al. [46] & Zambia & Perennial $^{\mathrm{a}}$ & $\begin{array}{l}\text { Quasi-experiment with } \\
\text { control }\end{array}$ & $\mathrm{tCHW}$ & M & $\begin{array}{c}\text { ITN + parasitological } \\
d x+T x+\text { referral }\end{array}$ \\
\hline Linn et al. [44] & Senegal & $\mathrm{Pf} A P I \geq 0.1 / 1000 \mathrm{pa}^{\mathrm{b}}$ & $\begin{array}{l}\text { Quasi-experiment with } \\
\text { control }\end{array}$ & $\mathrm{tCHW}$ & M & $\begin{array}{l}\text { Parasitological } \\
\quad d x+T x+\text { referral }+B C C\end{array}$ \\
\hline Littrell et al. [35] & Cameroon & Endemic and perennial ${ }^{a}$ & $\begin{array}{l}\text { Quasi-experiment with } \\
\text { control }\end{array}$ & $\mathrm{tCHW}$ & M & $\begin{array}{l}\text { Parasitological } \\
d x+T x+\text { referral }\end{array}$ \\
\hline Mbonye et al. [56] & Uganda & Hyper-endemic $^{a}$ & $\begin{array}{l}\text { Quasi-experiment with } \\
\text { control }\end{array}$ & $\mathrm{tCHW}$ & M & $\begin{array}{l}\text { Presumptive } \\
d x+T x+\text { referral }\end{array}$ \\
\hline Mbonye et al. [32] & Uganda & Hyper-endemic ${ }^{a}$ & $\begin{array}{l}\text { Quasi-experiment with } \\
\text { control }\end{array}$ & $\mathrm{tCHW}$ & M & $\begin{array}{l}\text { Presumptive } \\
d x+T x+\text { referral }\end{array}$ \\
\hline Msyamboza [47] & Malawi & Pf API $\geq 0.1 / 1000 \mathrm{pa}^{\mathrm{b}}$ & $\begin{array}{l}\text { Quasi-experiment with } \\
\text { control }\end{array}$ & $\mathrm{tCHW}$ & M & $\begin{array}{c}\text { ITN + IRS + parasitological } \\
d x+T x+\text { referral }\end{array}$ \\
\hline $\begin{array}{l}\text { Ndyomugyenyi et al. } \\
\text { [58] }\end{array}$ & Uganda & $\mathrm{Pf} A P I \geq 0.1 / 1000 \mathrm{pa}^{\mathrm{b}}$ & $\begin{array}{l}\text { Quasi-experiment with } \\
\text { control }\end{array}$ & $\mathrm{tCHW}$ & M & $\begin{array}{l}\text { Presumptive } \\
d x+T x+\text { referral }\end{array}$ \\
\hline Tiono et al. [45] & Burkina Faso & Seasonala ${ }^{a}$ & $\begin{array}{l}\text { Quasi-experiment with } \\
\text { control }\end{array}$ & $\mathrm{tCHW}$ & M & Parasitological $d x+T x$ \\
\hline Das et al. [26] & India & $\mathrm{API}>5 / 1000 \mathrm{pa}^{\mathrm{a}}$ & Cluster randomized trial & $\mathrm{tCHW}$ & M & $\begin{array}{l}\text { Presumptive } \\
\mathrm{dx}+\mathrm{Tx}+\text { chemopro- } \\
\text { phylaxis }\end{array}$ \\
\hline Eriksen et al. [49] & Tanzania & Holo-endemic ${ }^{a}$ & Cluster randomized trial & $\mathrm{tCHW}$ & M & $\mathrm{IPTp}+\mathrm{BCC}$ \\
\hline Kweku et al. [34] & Ghana & $\begin{array}{l}\mathrm{PfAPI} \\
\mathrm{pa}^{\mathrm{b}} \geq 0.1 \text { per } 1000\end{array}$ & Cluster randomized trial & $\mathrm{tCHW}$ & M & $\begin{array}{l}\text { Presumptive } \\
\quad d x+T x+\text { referral }+B C C\end{array}$ \\
\hline Lemma et al. [43] & Ethiopia & Hypo-endemic $^{a}$ & Cluster randomized trial & $\mathrm{tCHW}$ & M & $\mathrm{ITN}+\mathrm{BCC}$ \\
\hline Ohnmar et al. [30] & Myanmar & Endemic $^{a}$ & Cluster randomized trial & $\mathrm{tCHW}$ & M & $\begin{array}{l}\text { Parasitological } \\
\qquad d x+T x+\text { referral }\end{array}$ \\
\hline Patouillard et al. [33] & Ghana & Seasonal ${ }^{a}$ & Cluster randomized trial & $\mathrm{tCHW}$ & M & $\begin{array}{l}\text { ITN + presumptive } \\
\quad \mathrm{dx}+\mathrm{T} x+\text { referral }+\mathrm{BCC}\end{array}$ \\
\hline Abegunde et al. [27] & Nigeria & High perennial $^{a}$ & Case-control study & iCCM & $M+{ }^{c}$ & $\begin{array}{l}\text { ITN + parasitologi- } \\
\text { cal dx+Tx+refer- } \\
\text { ral + BCC+IPTp }\end{array}$ \\
\hline Brenner et al. [28] & Uganda & $\begin{array}{l}\text { Pf API } \geq 0.1 \text { per } 1000 \\
p^{b}{ }^{b}\end{array}$ & $\begin{array}{l}\text { Quasi-experiment with } \\
\text { control }\end{array}$ & iCCM & $M+^{d}$ & $\begin{array}{l}\text { Parasitological } \\
\quad d x+T x+\text { referral }+B C C\end{array}$ \\
\hline Mubiru et al. [38] & Uganda & $\begin{array}{l}\mathrm{PfAPI} \\
\mathrm{pa}^{\mathrm{b}} \geq 0.1 \text { per } 1000\end{array}$ & $\begin{array}{l}\text { Quasi-experiment with } \\
\text { control }\end{array}$ & iCCM & $M+{ }^{d}$ & $\begin{array}{l}\text { Parasitological } \\
\quad d x+T x+\text { referral }+B C C\end{array}$ \\
\hline $\begin{array}{l}\text { Nsungwa-Sabiiti et al. } \\
\text { [37] }\end{array}$ & Uganda & $\begin{array}{l}\text { Holo-endemic to hyper- } \\
\text { endemic }^{\mathrm{a}}\end{array}$ & $\begin{array}{l}\text { Quasi-experiment with } \\
\text { control }\end{array}$ & HMM & $M+{ }^{d}$ & $\begin{array}{l}\text { Parasitological } \\
\quad \mathrm{dx}+\mathrm{Tx}+\text { referral }+\mathrm{BCC}\end{array}$ \\
\hline Thiam et al. [42] & Senegal & $\begin{array}{l}\operatorname{Pf} A P I \geq 0.1 \text { per } 1000 \\
p^{b}{ }^{b}\end{array}$ & $\begin{array}{l}\text { Quasi-experiment with } \\
\text { control }\end{array}$ & HMM & $M+{ }^{d}$ & $\begin{array}{l}\text { Presumptive } \\
\quad d x+T x+\text { referral }+B C C\end{array}$ \\
\hline Tobin-West et al. [31] & Nigeria & $\begin{array}{l}\text { Pf API } \geq 0.1 \text { per } 1000 \\
\text { pa }^{b}\end{array}$ & $\begin{array}{l}\text { Quasi-experiment with } \\
\text { control }\end{array}$ & HMM & $M+{ }^{e}$ & $\begin{array}{l}\text { Parasitological } \\
\quad \mathrm{dx}+\mathrm{Tx}+\text { referral }+\mathrm{BCC}\end{array}$ \\
\hline Chinbuah et al. [48] & Ghana, Guinea & Perennial ${ }^{a}$ & Cluster randomized trial & HMM & $M+^{f}$ & $\begin{array}{l}\text { Presumptive } \\
\quad d x+T x+\text { referral }+B C C\end{array}$ \\
\hline Kidane and Morrow [59] & Ethiopia & Hyper-endemic $^{a}$ & Cluster randomized trial & HMM & M & $\begin{array}{l}\text { Presumptive } \\
\quad d x+T x+\text { referral }+B C C\end{array}$ \\
\hline
\end{tabular}


Table 1 (continued)

\begin{tabular}{|c|c|c|c|c|c|c|}
\hline Author & Country & Malaria transmission & Design & Model & $\begin{array}{l}\text { Malaria (M) } \\
\text { or malaria } \\
\text { plus }(\mathrm{M}+)\end{array}$ & $\begin{array}{l}\text { Malaria intervention } \\
\text { delivered }\end{array}$ \\
\hline Kouyaté et al. [39] & Burkina Faso & Holo-endemic ${ }^{a}$ & Cluster randomized trial & HMM & $M$ & $\begin{array}{l}\text { Parasitological } \\
\qquad \mathrm{dx}+\mathrm{Tx}+\text { referral }+\mathrm{BCC}\end{array}$ \\
\hline $\begin{array}{l}\text { The CDI Study Group } \\
\text { [29] }\end{array}$ & $\begin{array}{l}\text { Cameroon, } \\
\text { Nigeria and } \\
\text { Uganda }\end{array}$ & $\begin{array}{l}\text { Pf API } \geq 0.1 \text { per } 1000 \\
p^{b}\end{array}$ & Cluster randomized trial & HMM & $M+9$ & ITN, presumptive $d x+T x$ \\
\hline
\end{tabular}

pa, per annum; BCC, behavioural change communication/health education activities; Chemoprophylaxis, provision of malaria chemoprophylaxis; IPTc, intermittent preventive treatment (children); IPTp, intermittent preventive treatment (pregnant mothers); IRS, indoor residual spraying; ITN, long-lasting insecticidal nets or insecticide treated net distribution and/or organization for distribution by CHW and/or net dipping; Presumptive dx, malaria diagnosis by clinical signs and symptoms by $\mathrm{CHWs}$; Parasitological dx, malaria diagnosis by a parasitological method either rapid diagnostic test, microscopy or polymerase chain reaction or others by $\mathrm{CHWs}$;

Referral, referral of malaria cases as per the guidelines; Tx, malaria treatment by CHWs

a Self-reported in the paper

b Derived from Malaria Atlas Project [21] Map

c Primary health care

d Pneumonia, diarrhoea

e Pneumonia, diarrhoea, malnutrition

f Diarrhoea

g Vitamin A supplementation, Short-course, directly-observed treatment for Tuberculosis, Ivermectin distribution

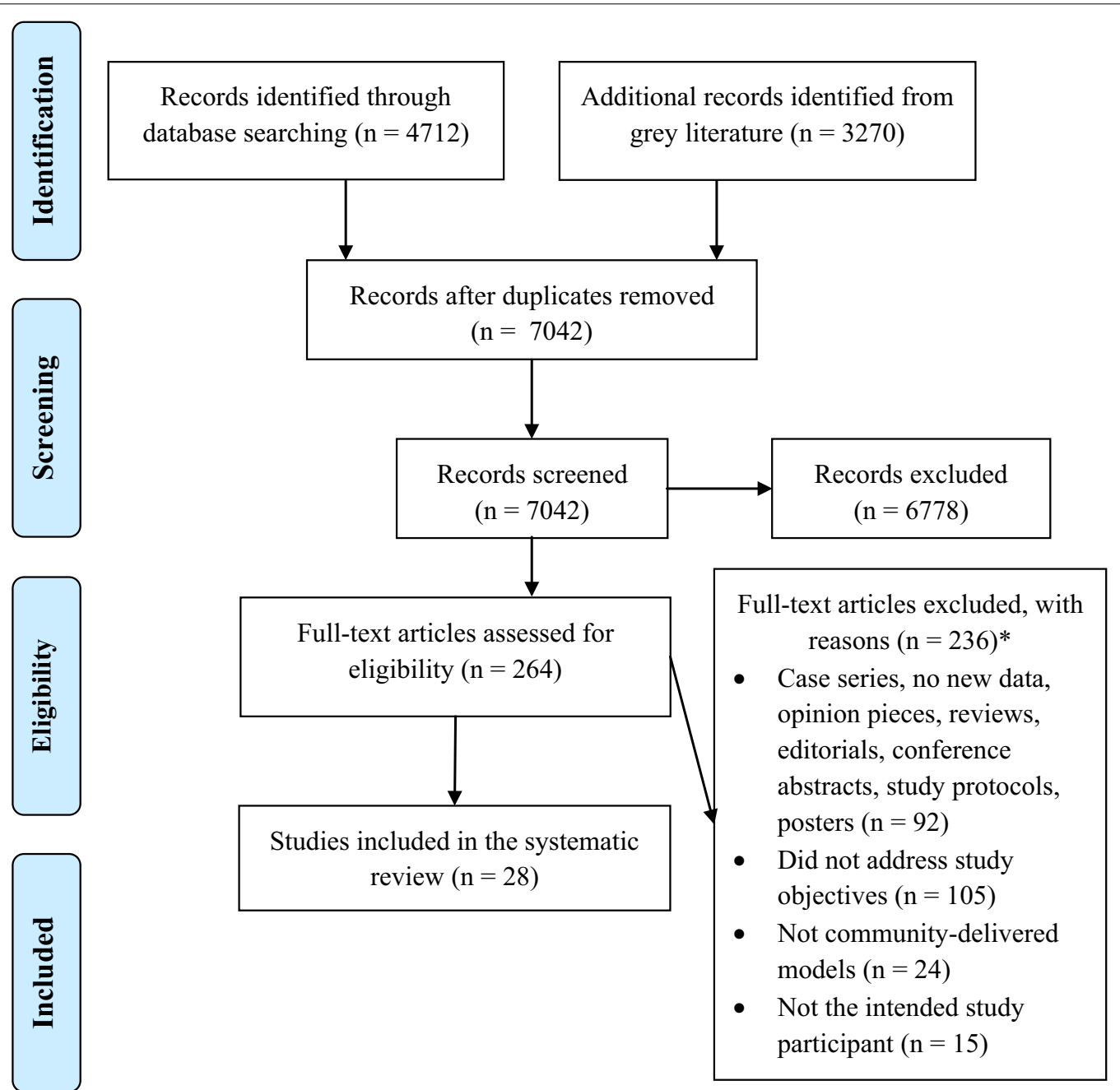

Fig. 1 PRISMA 2009 flow diagram [55]. *Excluded papers with reasons are available in Additional file 4 
included peer-reviewed publications and grey literature such as evaluation reports, policy guidelines and strategy documents (Additional file 3 ). The reference lists of the included papers were also reviewed. The first author (WHO) independently screened studies for inclusion (Fig. 1).

\section{Data extraction and analysis}

Two independent authors (WHO and KM) extracted data using a proforma for quantitative synthesis (Additional file 2). Discrepancies were resolved through discussion with a third author (FJIF). If further information was required that was not featured in the literature, authors were contacted up to two times via email.

The outcomes of interest were malaria intervention coverage (number and/or percentage, or other measures of malaria service uptake such as bed net ownership (insecticide-treated net (ITN) ownership $\geq 1$ /household) and actual usage (ITN use (the previous night) by anyone in the household), intermittent preventive treatment in pregnancy (IPTp) coverage (pregnant women who completed two doses of sulfadoxine-pyrimethamine), appropriate and timely (treatment within $24 \mathrm{~h}$ after onset of fever) treatment for fever of under-5 children) and malaria metric indices (number and/or percentage of malaria infection (hyperparasitaemia defined as parasite density $7000 / \mu \mathrm{l}$ and parasitaemia as $5000 / \mu \mathrm{l}$ and over, or more than or equal to 2000 asexual forms of Plasmodium falciparum per $\mathrm{mm}^{3}$ in the blood detected by microscopy), cases and death, fever (body temperature more than $37.5{ }^{\circ} \mathrm{C}$ or reported fever cases) and anaemia $(\mathrm{Hb}<8.0 \mathrm{~g} / \mathrm{dl}$ or haematocrit $\leq 24 \%))$.

Quality assessments were conducted by the first author (WHO). Risk of bias in non-randomized quantitative studies was assessed using The Risk Of Bias In Non-randomized Studies-of Interventions (ROBINS-I) assessment tool [22]. For randomized studies, The Cochrane Collaboration's tool for assessing risk of bias [23] was used.

Meta-analyses were performed to obtain pooled estimates of each outcome overall and by communitydelivered model strata (iCCM, HMM and tCHW). Between-study heterogeneity was assessed using the I-squared value [24]. Pooled estimates for each outcome were calculated using either a fixed-effects (where I-squared $\leq 30 \%$ ) or random-effects model (I-squared $=31-75 \%)$. Results were not pooled if heterogeneity was high (I-squared $>75 \%$ ). In the fixed-effects models, pooled effects estimates were weighted by the inverse of the individual study standard error. In randomeffects models, a between-study variance component was incorporated into the study weights [25]. Metaanalyses calculated relative differences in risk (RR) based on the absolute numbers extracted from each study and using the formula (intervention numerator/intervention denominator)/(control numerator/control denominator) between intervention populations $(\mathrm{CHW}$ provided interventions) and comparator/control populations (other service provider provided interventions) in the follow up phases of experimental studies. Meta-analyses were stratified by community-delivered models and presented in forest plots for each unique coverage and impact indicator. The coverage and impact indicators were defined according to the defined and measured outcomes in the included studies. Due to the small number of papers included in the meta-analyses, sensitivity analyses were not done. All analyses were undertaken using the Stata version 13 statistical software package (V13; StataCorp, College Station, TX, USA).

\section{Results}

In total, 7042 unique records were identified from five databases and grey literature searches. After screening of titles and abstracts, 264 full-text articles were assessed for eligibility, and of these 28 quantified the impact of community-delivered models on coverage and malariametric indices and were included in the quantitative data synthesis (Fig. 1).

Table 1 summarizes the 28 included studies $(\mathrm{tCHW}=18, \mathrm{iCCM}=3$ and $\mathrm{HMM}=7)$ which investigated community-delivered malaria interventions. In most studies $(n=21)$, CHW provided malaria diagnosis, treatment and referral, whereas the remaining 7 studies provided IPT or bed net distributions by CHW. CHW only provided services for malaria in $\mathrm{HCHW}$ and HMM models; additional diagnosis, treatment and referral services for other diseases from $\mathrm{CHW}$ were available in the iCCM model. The majority of studies were conducted in Africa $(n=25)$, mostly in hyper/holoendemic settings, and 3 studies were conducted in Asia, which were typically performed in hypo/mesoendemic settings. Study designs were cluster-randomized trials $(n=10)$, quasiexperimental studies with control $(\mathrm{n}=16)$, case control studies $(n=1)$ and retrospective cohort study $(n=1)$. Risk of bias was largely assessed as moderate for randomised studies (10/10) and moderate-to-serious for non-randomized studies (16/18) (Additional file 5). 15 studies reported coverage outcomes and 13 studies reported malaria-metric outcomes of $\mathrm{CHW}$ compared to non-community-delivered models.

\section{Impact of community-delivered models on coverage of malaria interventions Bed net coverage}

There was considerable heterogeneity (I-squared $=88.6 \%$ ) in 4 studies quantifying the effect of community-delivered models on household bed net ownership (ITN 
ownership $\geq 1$ /household) compared to non communitydelivered models (interventions provided by non-CHW service providers) so results were not pooled. Estimates ranged from no association in one study investigating tCHW $(\mathrm{RR}=1.00$; 95\% CI 0.93, 1.07) [26], to 1.14 times higher (95\% CI 1.05, 1.23) [27] and 1.34 times higher (95\% CI 1.13, 1.59) [28] risk of bed net ownership in two studies investigating iCCM, to a 1.54 (95\% CI 1.28, 1.86) times higher risk in one study [29] investigating HMM compared to the non-CHW arms (the control) (Fig. 2).

Meta-analysis of two studies [26, 30] showed positive association between tCHW models of ITN distribution on ITN use (the previous night) by anyone in the household (pooled RR $=1.0495 \%$ CI 1.01, 1.08; I-squared $=0 \%$ ) compared to the non-CHW arm (Fig. 2). There was considerable heterogeneity in three studies quantifying the effect of community-delivered models on ITN use (the previous night) by under- 5 children compared to non- community-delivered model (I-squared $=93.2 \%$ ). Estimates ranged from no association in one study investigating tCHW (RR=1.03; 95\% CI 0.93, 1.13) [26], 1.51 times $(95 \%$ CI 1.22, 1.87) [31] and 1.79 times (95\% CI 1.44, 2.24) [29] higher risk of under-5 ITN use in HMM arm compared to the non-CHW arm (Fig. 2).

\section{IPT coverage in pregnant women and children}

Meta-analysis that pooled three studies using the $\mathrm{tCHW}$ model (Fig. 3), demonstrated a $37 \%$ increase in IPT coverage in pregnancy (IPTp) (pregnant women who completed two doses of sulfadoxine-pyrimethamine in the tCHW arm compared to the non-CHW arm (IPTp from other providers) ( $R R=1.3795 \%$ CI 1.29, 1.44; I-squared $=0.0 \%$ ). One further study demonstrated that delivery of IPTp (defined as first dose of sulfadoxinepyrimethamine in 2nd trimester) was $16.3 \%$ higher in the tCHW intervention arm compared to non-CHW arm $(R R=1.1695 \%$ CI 1.15, 1.17) [32]. Two studies investigated the association between tCHW model and coverage of IPT in children (children who received all four courses of IPT) and both showed no association $(\mathrm{RR}=1.03(95 \% \mathrm{CI} 0.92,1.16)[33]$ and OR $1.18(95 \% \mathrm{CI}$ $0.62,2.22)[34])$.

\section{Children who received appropriate or timely treatment for fever}

Meta-analysis found high heterogeneity among the five studies using tCHW $(n=2)$ and HMM $(n=3)$ to assess appropriate treatment (Fig. 3). It demonstrated that the relative risk of receiving appropriate treatment of fever for under-5 children increased in intervention arm (CHW provided services) compared to the non-CHW arm (other providers provided services) in one $\mathrm{tCHW}$ study $(\mathrm{RR}=1.8195 \% \mathrm{CI} 1.58,2.08)$ [35] and pooled analysis of 3 HMM studies ( $R R=1.8995 \%$ CI 1.60, 2.22 (I-squared $=35.3 \%)$. However, no association was found in another tCHW study $(\mathrm{RR}=1.01(95 \%$ CI $1.00,1.02)$ [36].

Meta-analysis also found high heterogeneity among five studies that assessed timely treatment (Fig. 3). The pooled analysis of two tCHW studies $[26,36] \mathrm{RR}=1.21$ (95\% CI 1.19, 1.24) and another study investigating HMM [31] $\mathrm{RR}=2.30(95 \% \mathrm{CI} 1.68,3.14)$ found that communitydelivered models significantly increased the coverage of under- 5 children receiving timely treatment for fever in $\mathrm{CHW}$ arm compared to non-CHW arm. However, one study investigating HMM [37] RR=1.11 (95\% CI 0.86 , 1.43) and another one for iCCM [38] RR $=0.96$ (95\% CI $0.90,1.03)$ had no difference in timely treatment for fever (under-5 children treated for fever within $24 \mathrm{~h}$ ) in intervention arm compared to non-CHW arms.

\section{Impact of community-delivered models on malaria-metric indices}

\section{Parasitaemia and hyperparasitaemia}

While heterogeneity prevented pooled analysis of five studies that assessed parasitaemia (I-squared $=93.4 \%$ ), all four studies that investigated the tCHW model showed reduced prevalence of parasitaemia (by 25-70\%) compared to non-CHW arms, while one study that used HMM [39] demonstrated no difference in parasitaemia when malaria services were distributed by HMM or noncommunity-delivered models $(\mathrm{RR}=1.0495 \% \mathrm{CI} 0.93$, 1.16) (Fig. 4).

There was also high heterogeneity in the three tCHW studies reporting hyperparasitaemia (I-squared $=87.5 \%$ ). tCHW provided services significantly reduced hyperparasitaemia (by $75 \%$ or more) in two studies compared

(See figure on next page.)

Fig. 2 Forest plot showing the association between use of CHW and coverage of insecticide treated bed net ownership and use. Plot shows risk ratios (RR), 95\% confidence intervals $(95 \% \mathrm{Cl})$ and inverse variance study weights (\% weight). Pooled results were calculated by fixed-effects $($-squared $\leq 30 \%)$ or random-effects (I-squared $=31 \%$ to $\leq 75 \%)$. Estimates were calculated from data in the papers. ITN ownership is defined as a household with at least one ITN, ITN use as ITN use (the previous night) by anyone and ITN use (the previous night) by under-5 children. Please note: results were not pooled in meta-analysis across different community-delivered models quantifying the effect of community-delivered models on ITN ownership or ITN use (the previous night) by under-5 children due to the high degree of heterogeneity (I-squared $=88.6 \%$ and $93.2 \%$, respectively) 


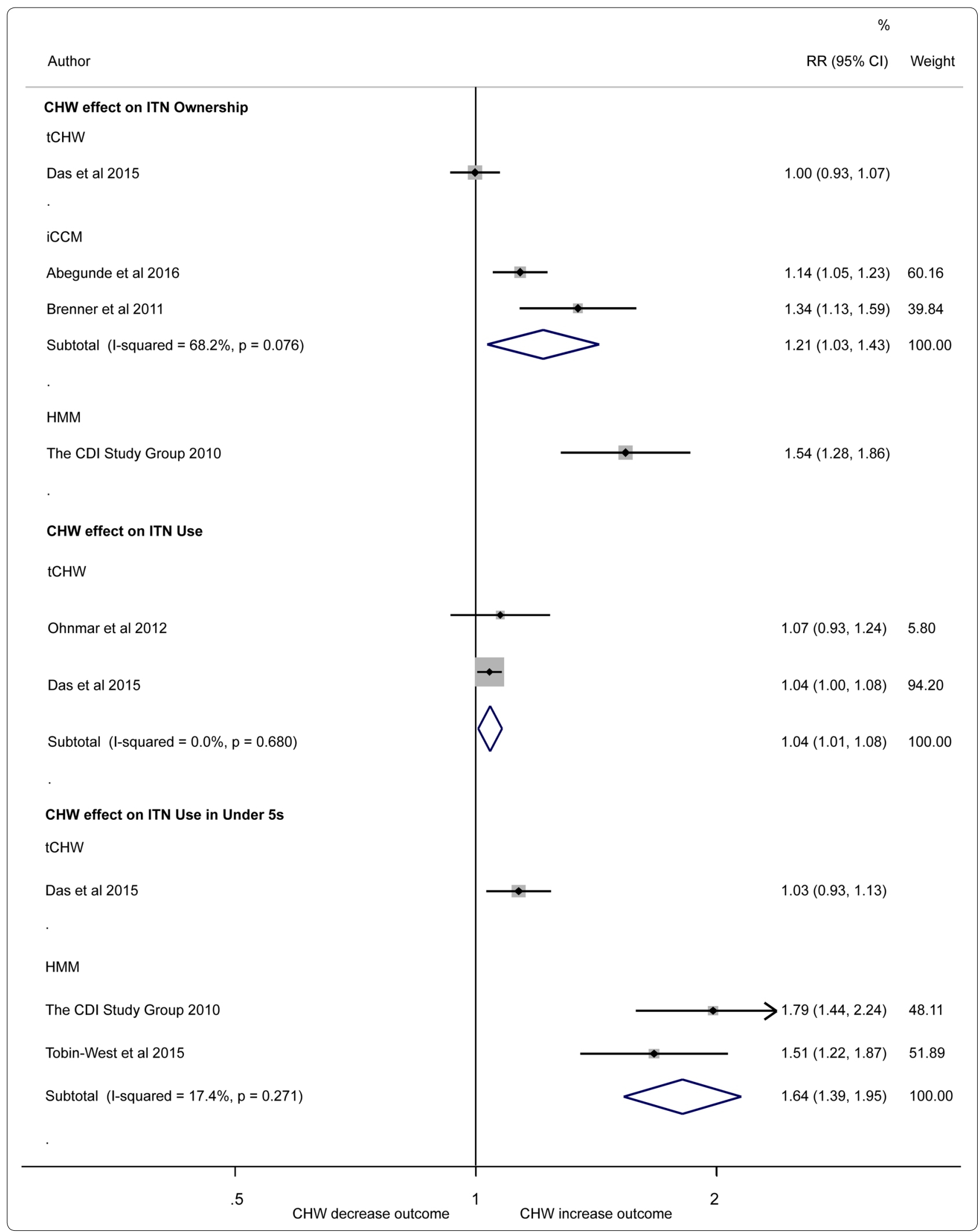




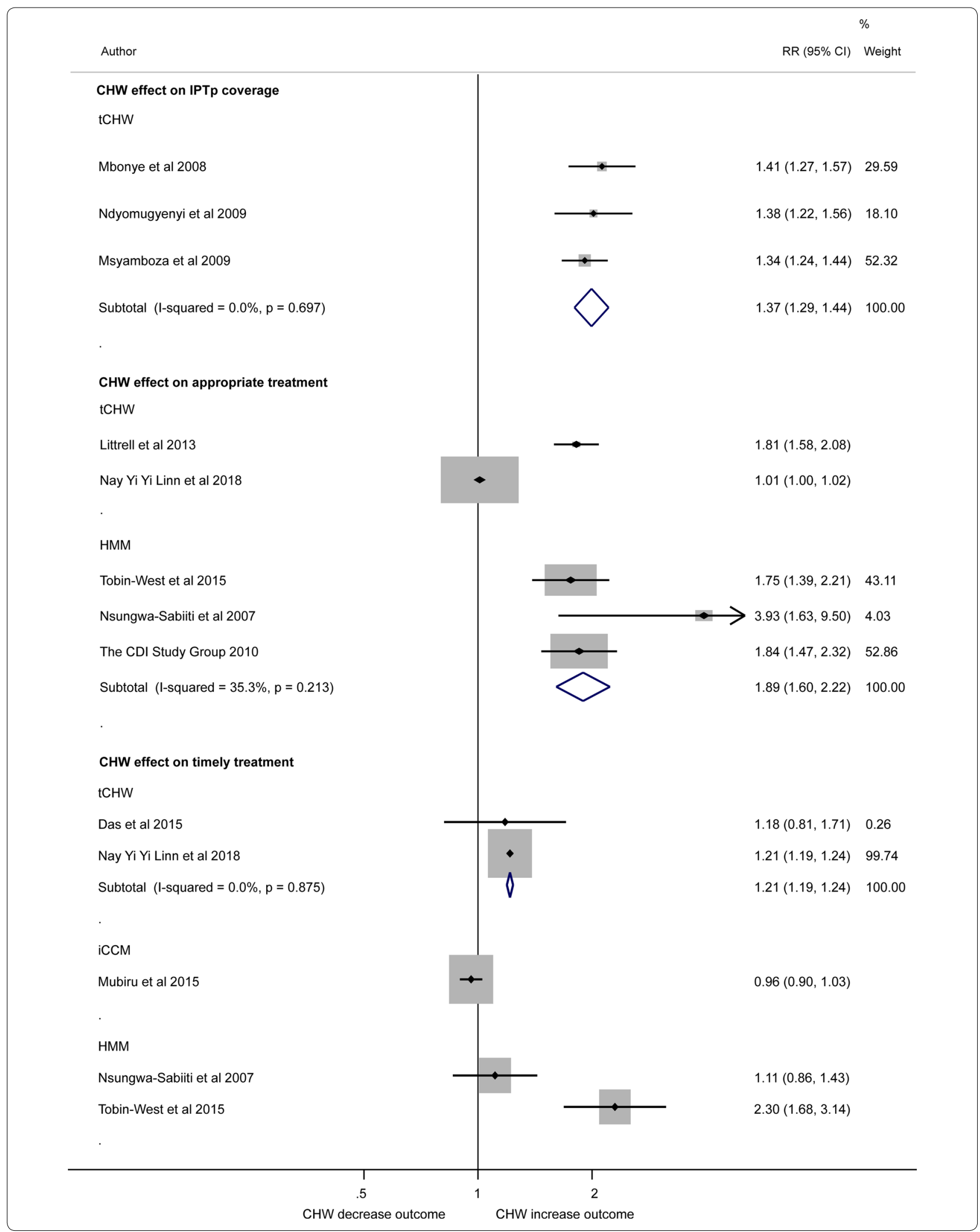


(See figure on previous page.)

Fig. 3 Forest plot showing inverse variance meta-analysis of the effect of CHW on IPT in pregnancy (2 doses) coverage; random effect analysis of the association between use of $\mathrm{CHW}$, and appropriate and timely (treatment within $24 \mathrm{~h}$ after onset of fever) treatment for fever on under-5 children. Plot shows risk ratios (RR), $95 \%$ confidence intervals ( $95 \% \mathrm{Cl}$ ) and inverse variance study weights (\% weight). Estimates were calculated from data in the papers. Please note: due to high heterogeneity results were not pooled across studies quantifying the effect of community-delivered models on appropriate treatment for fever on under- 5 children and timely treatment for fever on under- 5 children ( $(-$-squared $=96.9 \%$ and $=93.3 \%$, respectively)

to non- $\mathrm{CHW}$ arms, $\mathrm{RR}=0.25$ (95\% CI $0.10,0.66)$ [40] and $\mathrm{RR}=0.16(95 \% \mathrm{CI} 0.06,0.38)$ [41]. However, another study demonstrated increased risk of hyperparasitaemia in the tCHW group ( $\mathrm{RR}=12.2995 \% \mathrm{CI} 1.63,92.68)$ [34] (Fig. 4).

\section{Malaria cases}

Nine studies compared the effect of tCHW $(n=8)$ and HMM $(n=1)$ on difference in malaria caseload in the intervention arms compared to non-CHW arms. Between-study heterogeneity was extremely high (I-squared $=99.9 \%$ ) and HMM had negative effect (CHW arm had increased caseload) $\mathrm{RR}=1.12$ (95\% CI 1.10, 1.13) [42]. tCHW revealed positive effect ( $\mathrm{CHW}$ decrease malaria cases in the community) in three studies [40, 43, 44], negative results in four studies [34, 45-47] and no association in one study [36] (Fig. 5).

\section{Malaria mortality}

Both HMM and tCHW models in the meta-analysis $(n=7)$ showed that CHW intervention arms had lower malaria death rates compared to the nonCHW arms, with pooled $\mathrm{RR}=0.58$ (95\% CI 0.52, 0.65) (I-squared $=0.0 \%)$ (Fig. 5).

\section{Anaemia}

The four studies investigating the impact of the use of community-delivered model on the incidence of anaemia were methodologically diverse investigating specific high risk populations so meta-analyses were not performed (Fig. 6). One study showed that the relative risk of anaemia in under- 5 children was $78 \%$ lower $(R R=0.22,95 \%$ CI $0.13,0.36$ ) in the $\mathrm{tCHW}$ arm compared to non-CHW arm [48], conversely another tCHW study in the general population [49] found a Relative Risk (RR) $=4.8$ times higher $(95 \%$ CI 1.02, 22.57) and a tCHW study in multiparous pregnant women showed $\mathrm{RR}=1.47$ times higher (95\% CI 1.10, 1.97) in CHW arm compared to non CHW arm (with no effect seen in primiparous women) [47]. One study showed no association between HMM and anaemia in general population $(\mathrm{RR}=1.1395 \% \mathrm{CI} 0.85$, 1.51) [39].

\section{Fever}

Meta-analysis showed considerable heterogeneity between nine studies that compared the impact of the use of community-delivered models on fever prevalence compared to non-CHW arms. Effects by different community-delivered models showed no difference in HMM (RR 1.03 95\% CI 0.84, 1.26) [39], mixed results across five heterogeneous tCHW studies (two showed no effect, with RR 1.93 (95\% CI 0.97, 3.84) [49] and 1.04 (95\% CI $0.87,1.25)$ [32], while three studies revealed significant reduction of fever cases, with RR 0.58 (95\% CI 0.46 , 0.72) [48], 0.83 (95\% CI 0.74, 0.93) [30], and 0.11 (95\% CI $0.03,0.35$ ) [41], respectively), and mixed results for three iCCM studies (two studies found no association (RR 0.93 $95 \%$ CI $0.82,1.06)$ [27] and 1.02 (95\% CI 0.83, 1.24) [28]) while one study showed positive effect, $R R=0.82(95 \%$ CI 0.73, 0.93) [38] (Fig. 6).

\section{Discussion}

This review aimed to provide a holistic review of the impact of community-delivered models on all available outcome indicators for malaria intervention coverage and their impact on malaria metric indices. Implementation of community-delivered models (which included $\mathrm{CHW}$, HMM and iCCM) typically increased coverage of malaria interventions (such as bed nets and IPTp) and reduced the risk of parasitaemia and malaria-attributed mortality, but not proxy measures of malaria (such as fever and anaemia) compared to malaria interventions delivered by non-community-delivered models. There was significant methodological and statistical heterogeneity and variations in internal validity, of the included studies, which made meta-analysis and formal comparisons of the impact of different community-delivered models difficult. The majority of studies were conducted in high transmission settings in Africa, and focused on high risk sub-groups such as pregnant women and under-5 children, which has implications on the generalizability of findings to low transmission and elimination settings, such as areas in Asia, where the epidemiology of malaria is different.

Community-delivered models have been widely used to distribute bed nets and implement appropriate malaria diagnosis and treatment in the community. This review found that community-delivered models increased bed 


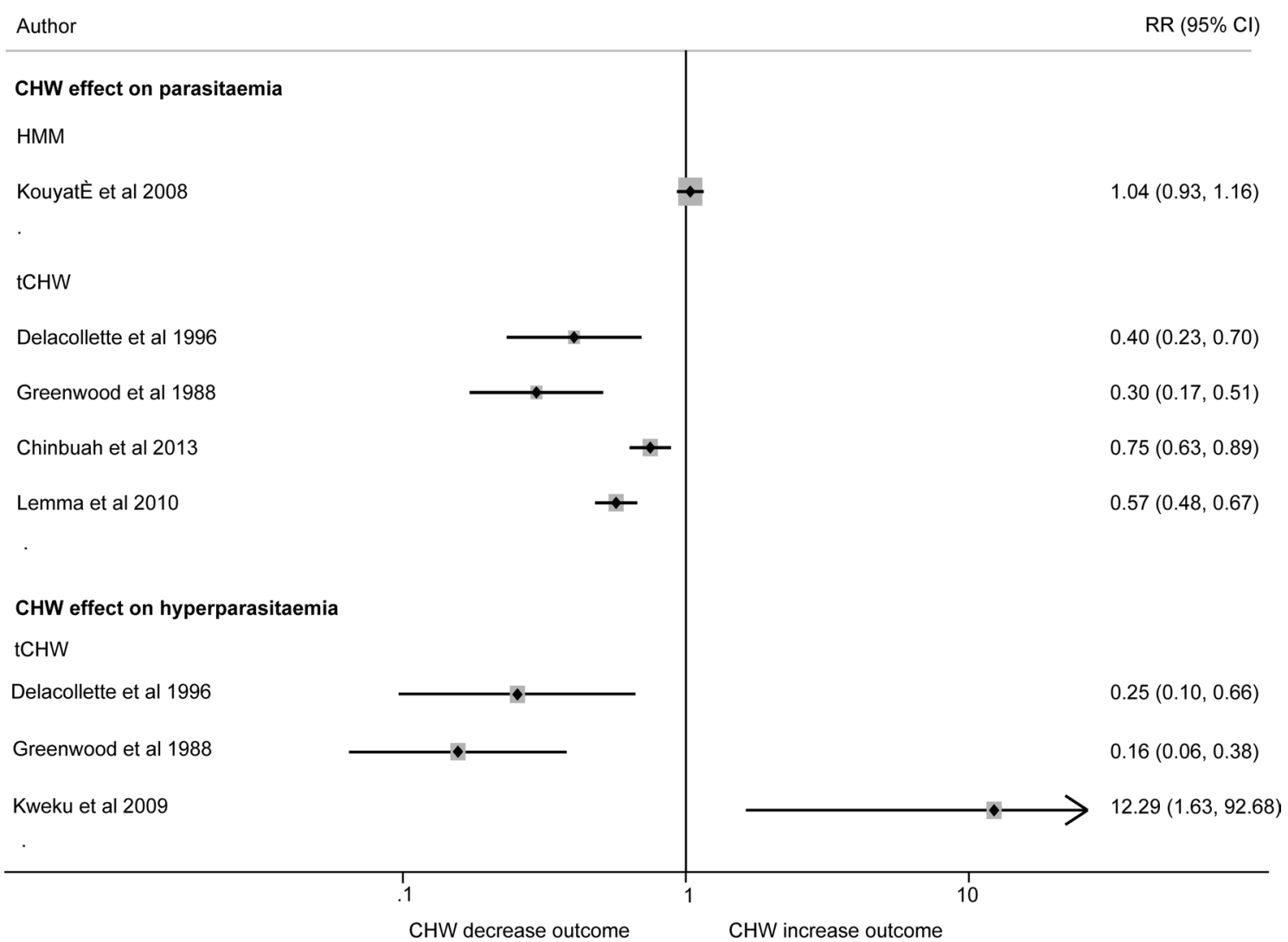

Fig. 4 Random effect analysis of the association between use of CHW and impact on parasitaemia and hyperparasitaemia. Plot shows risk ratios (RR) and 95\% confidence intervals $(95 \% \mathrm{Cl})$. Estimates were calculated from data in the papers. Parasitaemia was defined as presence of any malaria parasite species [40, 41, 43, 48], or P. falciparum [39] by microscopy. Hyperparasitaemia was defined as parasite density 7000/ $\mu$ l[34], parasitaemia $5000 / \mu l$ and over [41] and more than or equal to 2000 asexual forms of $P$. falciparum per mm [40] in the blood detected by microscopy. Due to high heterogeneity results were not pooled across studies quantifying the effect of community-delivered models on parasitaemia or hyperparasitaemia (I-squared $=93.4 \%$ and $87.5 \%$ respectively)

net coverage up to $54 \%$. The included papers attributed these improvements to the fact that CHW were local peer providers, received proper training and intensive supervision and were tasked with helping with the community mobilization and logistical aspects [28] and that CHW reduced the additional hindrances to accessing appropriate services in the field [50]. However, while large magnitudes of effect were observed for bed net coverage, pooled analysis demonstrated that community-delivered models only increased bed net usage by $4 \%$ compared to those delivered by non-community-delivered models. Encouraging and promoting proper use of malaria interventions, such as bed nets, over and above ensuring physical access to such interventions, should be a key component of community-delivered models to improve the use of malaria services in the community. This review also identified studies providing evidence for the delivery of less routinely delivered malaria interventions through community-delivered models. IPTp is typically distributed to pregnant women attending antenatal clinics and distribution through tCHW increased IPTp (2 dose) coverage (37\%) compared to antenatal clinics. This highlights that IPTp can be distributed successfully through tCHW and could fulfil service gaps in countries where IPTp is policy. Overall, this review provides evidence for the advantage of community-delivered models over noncommunity-delivered models for malaria control and possible expansion of malaria services through community channels to supplement facility based services.

Implementation of community-delivered models also had a positive impact on parasitaemia and malaria-attributed mortality, but not proxy malaria metric measures, such as anaemia and fever. Community-delivered models reduced the risk of parasitaemia (from 25 to $70 \%$, for tCHW only) and malaria-attributed mortality (by $42 \%$ in pooled analysis) compared to non-community- delivered models. All tCHW studies [40, 41, 43, 48] that demonstrated a significant reduction of parasitaemia in the community specified the use of a simple treatment algorithm (adapted from a national/international guideline) 


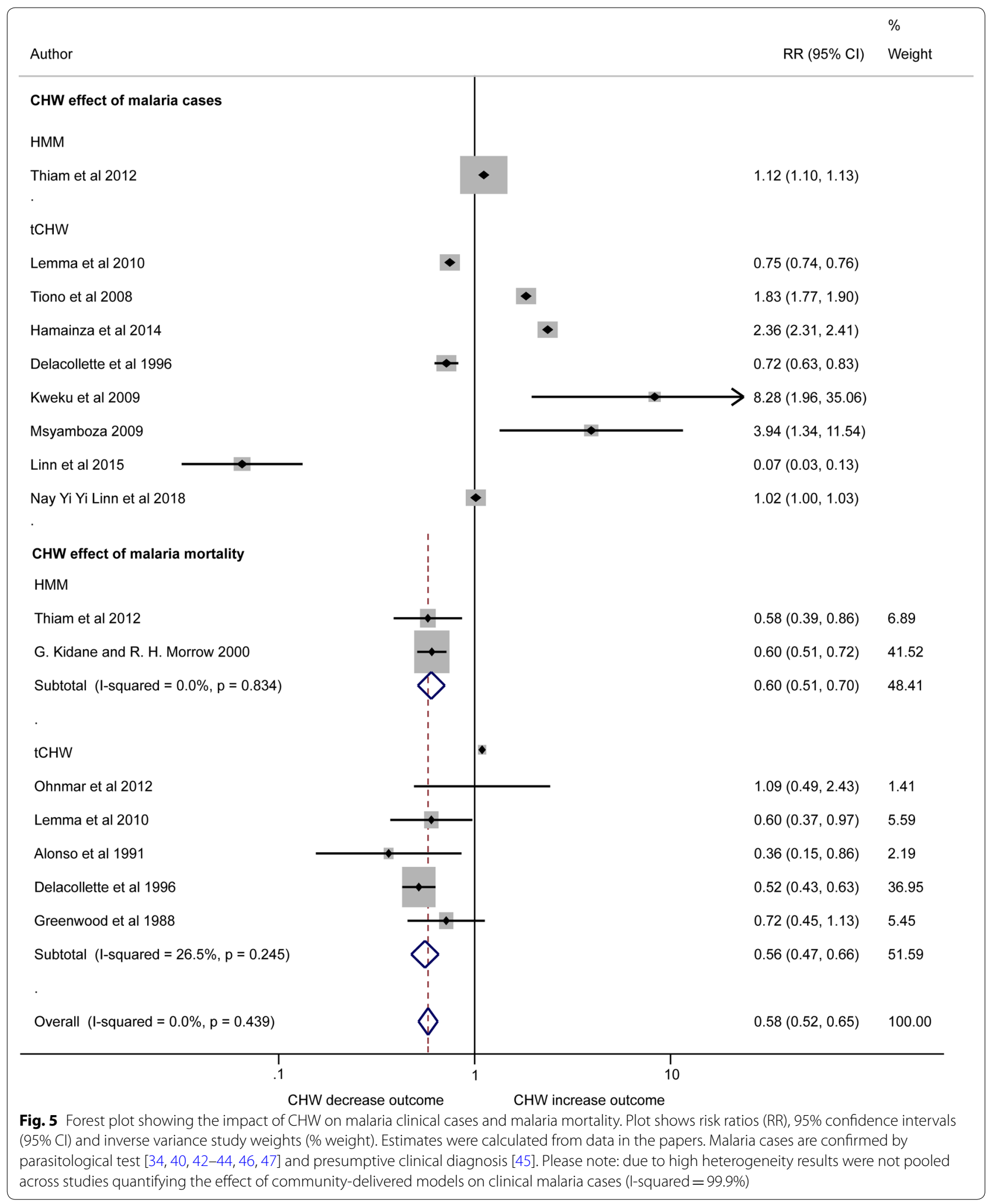




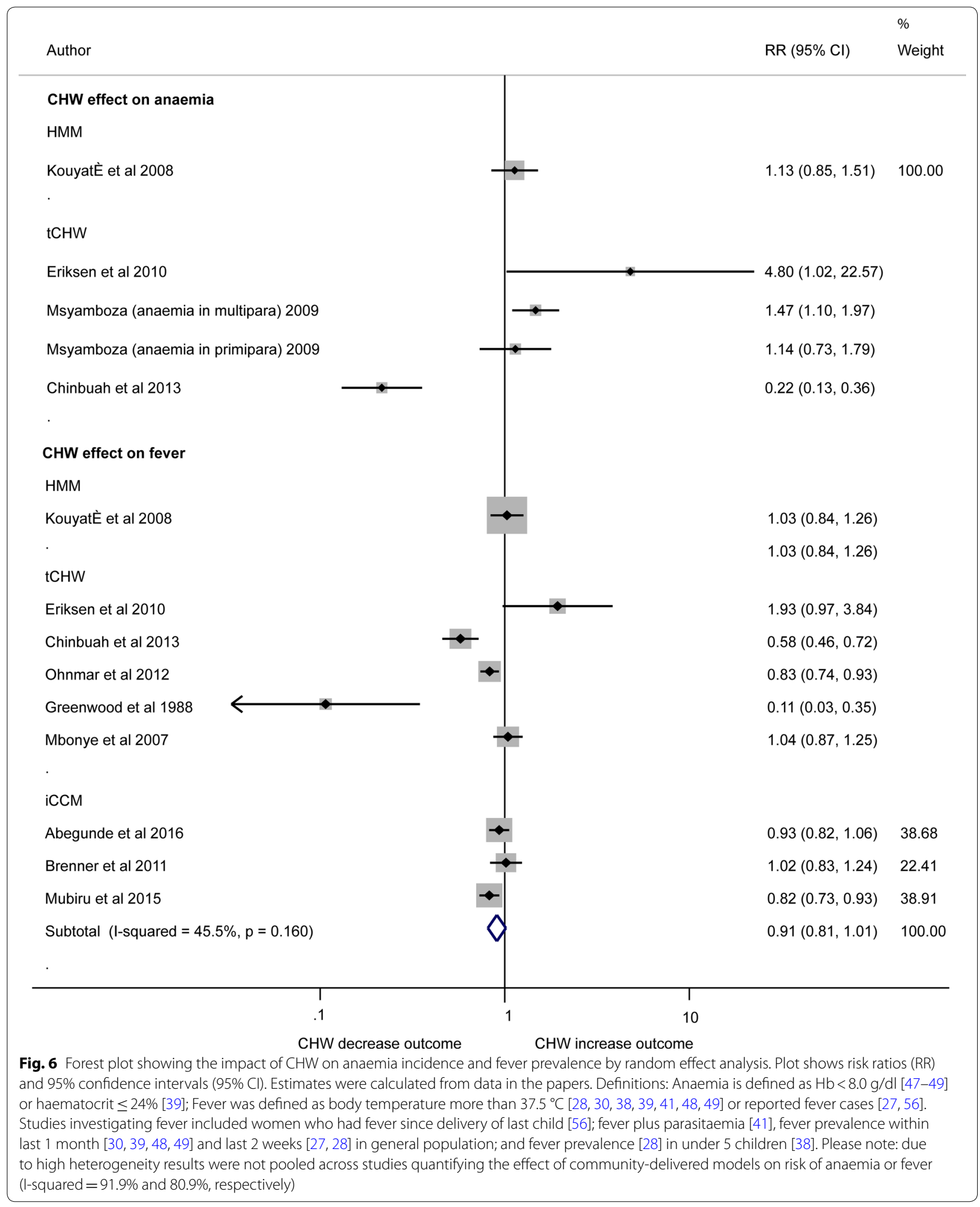


to be followed by CHWs. In the studies that demonstrated a reduction of malaria-attributed mortality, $\mathrm{CHW}$ provided malaria diagnosis, appropriate treatments and referral services according to the national guidelines (but no simplified algorithm specified). Therefore, the national malaria management guideline of an endemic country should be simplified and CHWs supported so that community-delivered models yield direct impacts on malaria-metrics indices.

The positive impact of community-delivered models on increasing malaria services coverage, and reducing parasitaemia and malaria mortality were consistent despite methodological heterogeneity between studies, which strengthens the evidence for the use of community-delivered models to deliver malaria services. However, heterogeneity observed across studies that evaluated proxy indicators of malaria (anaemia and fever) contributed to the lack of clear overall effect. This was most likely due to methodological heterogeneity in the community models utilized (tCHW, iCCM and HMM), to differences in the malaria interventions delivered in community-delivered models, and in the comparison groups used, all of which made the studies unalike and difficult to compare. Interventions delivered by $\mathrm{CHW}$ for studies evaluating the impact on anaemia and fever were particularly diverse. For example, one study [49] only provided IPTp and behavioural change communication while others provided comprehensive malaria services, such as bed net distribution, parasitological diagnosis, treatment and referral of malaria cases [46]. In addition to heterogeneity, evaluation of bias revealed that the included studies were moderately to seriously biased, which would have impacted on the internal validity of the findings as well as strength and directions of estimates. Other sources of bias should also be considered. While publication bias could not be assessed adequately in this review due to the small number of studies in each analysis, publication bias may still have affected the number of studies included as well as the direction of estimates of effect. However, this bias was mitigated by including searches of the grey literature. Measurement of the aetiologies of anaemia and fever are multifactorial and the estimates were subject to information bias (for example, in the case of self-reported fever). The methodological heterogeneity and bias of included studies may affect the strength of the evidence of the use of community-delivered models for malaria control and elimination.

This review aimed to be as inclusive as possible and included all relevant and available studies regardless of language and dates of publication; previous published reviews, published up until 2014, were restricted to particular models, interventions, target populations or geographical areas and only a review included meta-analyses
[17]. This holistic systematic review enabled comparisons and quantification of heterogeneity across the aforementioned factors and performed meta-analyses including several more recently published studies. Compared to previous review findings the magnitudes of effect in pooled analyses of $\mathrm{CHW}$ on increasing coverage of bed nets $[11,17]$ and IPTp [11] and reducing the risk of parasitaemia $[10,11,17]$ and malaria attributed mortality $[10,15]$ were generally lower in this review as previous meta-analyses only included studies conducted in high transmission areas of sub-Saharan Africa and focused on high risk population groups.

However there were limitations in the range of geographical and malaria transmission settings, influence of factors independent of community-delivered models and integration of health services which may impact the generalizability of the findings in different contexts. Most studies were conducted in Africa and were undertaken in malaria control settings, with control-specific indicators such as malaria interventions coverage and disease burden. Elimination-specific indicators such as number of foci by classification, number of people and percentage of population living in active foci, and number of malaria deaths by species and by imported or locally acquired [51] were not included as none of the identified studies were undertaken in elimination setting. This gap highlights that the magnitude of effects of the communitydelivered models on coverage and malaria-metric indices might not be the same in the elimination settings of low transmission areas compared to control settings in the African Region.

Furthermore, the success of the community-delivered models in malaria control and elimination relies on implementation of the model such as assignment, recruitment, training, supportive supervision and ongoing technical support to CHWs, incentive for CHWs, and management structure in a ministry or an organization that manages $\mathrm{CHW}$ program which is nested in the broader and complex national health system. The generalizability of the findings from this review depends on health system factors independent of communitydelivered models, such as budget allocation, policy of intervention distribution in the respective country and effectiveness of the logistic and supply chain systems $[52,53]$. Therefore, caution is needed in translating the effectiveness of community-delivered models in different context-specific malaria programmes. Moreover, the community-delivered models identified in this review have limitations in the integration of services for common diseases in the community other than malaria. Only the iCCM model integrated services for common childhood illnesses; $\mathrm{tCHW}$ and HMM were primarily for malaria alone. Hence, the effectiveness of community-delivered 
models may vary depending on what other health interventions are included in the integrated community models. No integrated model combines interventions that cover both adult and child high-burden diseases in the global burden list; implementation and evaluation of such models in the malaria elimination setting represent a global research gap.

\section{Recommendations and conclusions}

Overall, the community-delivered model is an effective approach to control malaria in high transmission areas. However, community-delivered models need to be supported by a number of independent systematic factors such as country specific health system to make the model most effective in different country contexts. Currently, endemic countries use integrated community- delivered models although the knowledge on what health problems to be integrated optimally into the community-delivered model of each endemic country remains a gap. Moreover, elimination program-specific community-delivered models are yet to be implemented and evaluated as suggested in malERA: An updated research agenda for health systems and policy research in malaria elimination and eradication [54]. To maintain the effectiveness in elimination programs in the context of primary health care, community-delivered models need to be supported, advanced and adapted throughout the implementation of $\mathrm{CHW}$ recruitment, training, supportive supervision and ongoing technical support, and provision of incentives to CHWs, considering the changing malaria epidemiology, development of new tools and technologies, and dynamic political environment of each malaria endemic country. Further country-specific series of operational research for development of communitydelivered integrated malaria elimination model are essential in order to provide an evidence base for the integration of interventions for different diseases and to maintain the effectiveness of community-delivered model in national malaria elimination programme.

\section{Additional files}

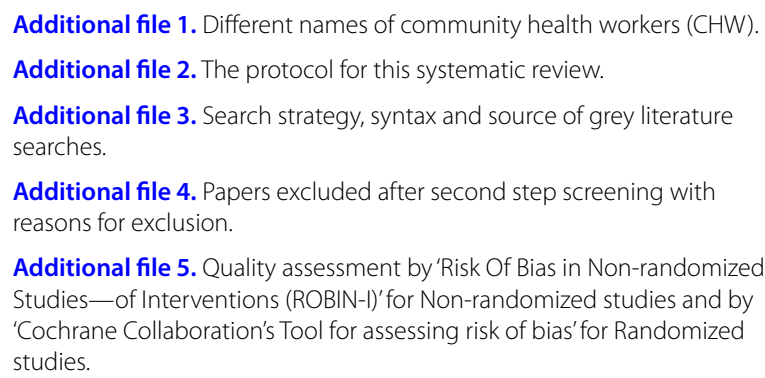

\section{Abbreviations}

ACT: artemisinin-based combination therapy; BCC: behavioural change communication; CHW: community health workers; HMM: home management of malaria; iCCM: integrated community case management; IPT: intermittent preventive treatment; IPTc: intermittent preventive treatment in children; IPTp: intermittent preventive treatment in pregnancy; ITN: insecticide treated net; LILACS: Latin American and Caribbean Health Sciences Literature; LLIN: long-lasting insecticidal net; M: malaria interventions; $\mathrm{M+}$ : malaria plus other diseases interventions; MOOSE: meta-analysis of observational studies in epidemiology; PRISMA: preferred reporting items for systematic reviews and meta-analyses; PROSPERO: international prospective register of systematic reviews; RDT: rapid diagnostic test; ROBINS-I: the risk of bias in non-randomized studies-of interventions; RR: relative risk; $\mathrm{tCHW}$ : traditional $\mathrm{CHW}$; WHO: World Health Organization.

\section{Acknowledgements}

Rachel West, Liaison Librarian, School of Exercise and Nutrition Sciences, School of Health and Social Development, Deakin Population Health SRC Library for assisting in literature search and retriveing articles online. Katherine O'Flaherty and Ellen Kearney for help with statistical analysis and figure preparation.

\section{Authors' contributions}

WHO, LG and FJIF designed the protocol and performed literature searches. WHO and KAM extracted and synthesised data. WHO and PA designed and undertook statistical analyses. All authors reviewed the paper, provided critical inputs. All authors read and approved the final manuscript.

\section{Funding}

This systematic review was funded by Deakin-Burnet PhD scholarship (to WHO), the Australian Research Council (Future Fellowship to FJIF) and the Australian National Health and Medical Research Council (Career Development Fellowship and Australian Centre for Research Excellence in Malaria Elimination to FJIF). The Burnet Institute is funded by a Victorian State Government Operational Infrastructure Support grant. The funders have no input on the design of the study, collection, analysis, interpretation and publication of the study results.

\section{Availability of data and materials}

All data generated or analysed during this study are included in this published article and its additional files.

\section{Ethics approval and consent to participate}

Not applicable.

\section{Consent for publication}

Not applicable.

\section{Competing interests}

The authors declare that they have no competing interests.

\section{Author details}

${ }^{1}$ School of Health and Social Development, Deakin University, 221 Burwood Hwy, Burwood, VIC 3125, Australia. ${ }^{2}$ Burnet Institute, 85 Commercial Rd, Melbourne, VIC 3004, Australia. ${ }^{3}$ Melbourne School of Population and Global Health, The University of Melbourne, 235 Bouverie St, Carlton, Melbourne, VIC 3053, Australia. ${ }^{4}$ Department of Epidemiology and Preventive Medicine, Monash University, Melbourne, VIC, Australia. ${ }^{5}$ Judith Lumley Centre, La Trobe University, Level 3, George Singer Building Bundoora, Melbourne, VIC 3086, Australia.

Received: 19 February 2019 Accepted: 30 July 2019

Published online: 06 August 2019

\section{References}

1. WHO. World Malaria Report 2018. Geneva: World Health Organization; 2018. p. 210. 
2. Cibulskis RE, Alonso P, Aponte J, Aregawi M, Barrette A, Bergeron L, et al. Malaria: global progress 2000-2015 and future challenges. Infect Dis Poverty. 2016;5:61.

3. Bhatt S, Weiss DJ, Cameron E, Bisanzio D, Mappin B, Dalrymple U, et al. The effect of malaria control on Plasmodium falciparum in Africa between 2000 and 2015. Nature. 2015;526:207-11.

4. WHO. Community health workers: What do we know about them? Geneva: World Health Organization; 2007.

5. WHO. World Malaria Report 2015. Geneva: World Health Organization; 2015.

6. Rasanathan K, Muniz M, Bakshi S, Kumar M, Solano A, Kariuki W, et al. Community case management of childhood illness in sub-Saharan Africa - findings from a cross-sectional survey on policy and implementation. J Global Health. 2014;4:020401.

7. CDI Study Group. Community-directed interventions for priority health problems in Africa: results of a multicountry study. Bull World Health Organ. 2009;88:481-560.

8. McCord GC, Liu A, Singh P. Deployment of community health workers across rural sub-Saharan Africa: financial considerations and operational assumptions. Bull World Health Organ. 2013;91:244-53.

9. Awor P, Miller J, Peterson S. Systematic literature review of integrated community case management and the private sector in Africa: relevant experiences and potential next steps. J Global Health. 2014;4:020414.

10. Christopher JB, Le May A, Lewin S, Ross DA. Thirty years after Alma-Ata: a systematic review of the impact of community health workers delivering curative interventions against malaria, pneumonia and diarrhoea on child mortality and morbidity in sub-Saharan Africa. Human Res Health. 2011;9:27.

11. Gilmore B, McAuliffe E. Effectiveness of community health workers delivering preventive interventions for maternal and child health in lowand middle-income countries: a systematic review. BMC Public Health. 2013;13:847.

12. Hopkins H, Talisuna A, Whitty CJ, Staedke SG. Impact of home-based management of malaria on health outcomes in Africa: a systematic review of the evidence. Malar J. 2007:6:134.

13. Kamal-Yanni MM, Potet J, Saunders PM. Scaling-up malaria treatment: a review of the performance of different providers. Malar J. 2012;11:414.

14. Okwundu Cl, Nagpal S, Musekiwa A, Sinclair D. Home- or communitybased programmes for treating malaria. Cochrane Database Syst Rev. 2013;5:CD009527.

15. Paintain LS, Willey B, Kedenge S, Sharkey A, Kim J, Buj V, et al. Community health workers and stand-alone or integrated case management of malaria: a systematic literature review. Am J Trop Med Hyg. 2014;91:461-70

16. Ruizendaal E, Dierickx S, Peeters Grietens K, Schallig HD, Pagnoni F, Mens PF. Success or failure of critical steps in community case management of malaria with rapid diagnostic tests: a systematic review. Malar J. 2014:13:229.

17. Salam RA, Das JK, Lassi ZS, Bhutta ZA. Impact of community-based interventions for the prevention and control of malaria on intervention coverage and health outcomes for the prevention and control of malaria. Infect Dis Poverty. 2014;3:25.

18. Glenton C, Colvin CJ, Carlsen B, Swartz A, Lewin S, Noyes J, et al. Barriers and facilitators to the implementation of lay health worker programmes to improve access to maternal and child health: qualitative evidence synthesis. Cochrane Database Syst Rev. 2013;10:CD010414.

19. Liberati A, Altman DG, Tetzlaff J, Mulrow C, Gotzsche PC, loannidis JP, et al. The PRISMA statement for reporting systematic reviews and meta-analyses of studies that evaluate health care interventions: explanation and elaboration. PLoS Med. 2009;6:e1000100.

20. Stroup DF, Berlin JA, Morton SC, Olkin I, Williamson GD, Rennie D, et al, Meta-analysis of observational studies in epidemiology: a proposal for reporting. Meta-analysis of observational studies in epidemiology (MOOSE) group. JAMA. 2000;283:2008-12.

21. Gething PW, Patil AP, Smith DL, Guerra CA, Elyazar IR, Johnston GL, et al. A new world malaria map: plasmodium falciparum endemicity in 2010. Malar J. 2011;10:378.

22. Sterne JA, Hernán MA, Reeves BC, Savović J, Berkman ND, Viswanathan M, et al. ROBINS-I: a tool for assessing risk of bias in non-randomised studies of interventions. BMJ. 2016;355:i4919.
23. Higgins JPT, Altman DG, Gøtzsche PC, Jüni P, Moher D, Oxman AD, et al. The Cochrane Collaboration's tool for assessing risk of bias in randomised trials. BMJ. 2011;343:d5928.

24. Higgins JPT, Thompson SG, Deeks JJ, Altman DG. Measuring inconsistency in meta-analyses. BMJ. 2003;327:557-60.

25. DerSimonian R, Laird N. Meta-analysis in clinical trials. Control Clin Trials. 1986;7:177-88.

26. Das A, Friedman J, Kandpal E, Ramana GNV, Das Gupta RK, Pradhan MM, et al. Strengthening malaria service delivery through supportive supervision and community mobilization in an endemic Indian setting: an evaluation of nested delivery models. Malar J. 2014;13:482.

27. Abegunde D, Orobaton N, Bassi A, Oguntunde O, Bamidele M, Abdulkrim $M$, et al. The impact of integrated community case management of childhood diseases interventions to prevent malaria fever in children less than five years old in Bauchi State of Nigeria. PLoS ONE. 2016;1 1:e0148586.

28. Brenner JL, Kabakyenga J, Kyomuhangi T, Wotton KA, Pim C, Ntaro M, et al. Can volunteer community health workers decrease child morbidity and mortality in southwestern Uganda? An impact evaluation. PLoS One. 2011;6:e27997.

29. The CDI Study Group. Community-directed interventions for priority health problems in Africa: results of a multicountry study. Bull World Health Organ. 2010;88:509-18.

30. Ohnmar A, Tun M, San S, Than W, Chongsuvivatwong V. Effects of malaria volunteer training on coverage and timeliness of diagnosis: a cluster randomized controlled trial in Myanmar. Malar J. 2012;11:309.

31. Tobin-West $\mathrm{Cl}$, Briggs $\mathrm{N}$. Effectiveness of trained community volunteers in improving knowledge and management of childhood malaria in a rural area of Rivers State. Nigeria. Nigerian J Clin Pract. 2015;18:651-8.

32. Mbonye AK, Bygbjerg I, Magnussen P. Intermittent preventive treatment of malaria in pregnancy: a community-based delivery system and its effect on parasitemia, anemia and low birth weight in Uganda. Int J Infect Dis. 2008;12:22-9.

33. Patouillard E, Conteh L, Webster J, Kweku M, Chandramohan D, Greenwood B. Coverage, adherence and costs of intermittent preventive treatment of malaria in children employing different delivery strategies in Jasikan. Ghana. PLoS One. 2011;6:e24871.

34. Kweku M, Webster J, Adjuik M, Abudey S, Greenwood B, Chandramohan D. Options for the delivery of intermittent preventive treatment for malaria to children: a community randomised trial. PLOS ONE. 2009;:4:e7256.

35. Littrell M, Moukam LV, Libite R, Youmba JC, Baugh G. Narrowing the treatment gap with equitable access: mid-term outcomes of a community case management program in Cameroon. Health Policy Plan. 2013:28:705-16.

36. Linn NYY, Kathirvel S, Das M, Thapa B, Rahman MM, Maung TM, et al. Are village health volunteers as good as basic health staffs in providing malaria care? A country wide analysis from Myanmar, 2015. Malar J. 2018;17:242.

37. Nsungwa-Sabiiti J, Peterson S, Pariyo G, Ogwal-Okeng J, Petzold MG, Tomson G. Home-based management of fever and malaria treatment practices in Uganda. Trans R Soc Trop Med Hyg. 2007;101:1199-207.

38. Mubiru D, Byabasheija R, Bwanika JB, Meier JE, Magumba G, Kaggwa FM, et al. Evaluation of integrated community case management in eight districts of central Uganda. PLoS ONE. 2015;10:e0134767.

39. Kouyaté B, Somé F, Jahn A, Coulibaly B, Eriksen J, Sauerborn R, et al. Process and effects of a community intervention on malaria in rural Burkina Faso: randomized controlled trial. Malar J. 2008;7:50.

40. Delacollette C, Van der Stuyft P, Molima K. Using community health workers for malaria control: experience in Zaire. Bull World Health Organ. 1996;74:423-30.

41. Greenwood BM, Greenwood AM, Bradley AK, Snow RW, Byass P, Hayes RJ, et al. Comparison of two strategies for control of malaria within a primary health care programme in the Gambia. Lancet. 1988;1:1121-7.

42. Thiam S, Thwing J, Diallo I, Fall FB, Diouf MB, Perry R, et al. Scale-up of home-based management of malaria based on rapid diagnostic tests and artemisinin-based combination therapy in a resource-poor country: results in Senegal. Malar J. 2012;11:334.

43. Lemma H, Byass P, Desta A, Bosman A, Costanzo G, Toma L, et al. Deploying artemether-lumefantrine with rapid testing in Ethiopian communities: impact on malaria morbidity, mortality and healthcare resources. Trop Med Int Health. 2010;15:241-50. 
44. Linn AM, Ndiaye Y, Hennessee I, Gaye S, Linn P, Nordstrom K, et al. Reduction in symptomatic malaria prevalence through proactive community treatment in rural Senegal. Trop Med Int Health. 2015;20:1438-46.

45. Tiono AB, Kabore Y, Traore A, Convelbo N, Pagnoni F, Sirima SB. Implementation of Home based management of malaria in children reduces the work load for peripheral health facilities in a rural district of Burkina Faso. Malar J. 2008;7:201.

46. Hamainza B, Moonga H, Sikaala CH, Kamuliwo M, Bennett A, Eisele TP, et al. Monitoring, characterization and control of chronic, symptomatic malaria infections in rural Zambia through monthly household visits by paid community health workers. Malar J. 2014;13:128.

47. Msyamboza KP, Savage EJ, Kazembe PN, Gies S, Kalanda G, D'Alessandro $U$, et al. Community-based distribution of sulfadoxine-pyrimethamine for intermittent preventive treatment of malaria during pregnancy improved coverage but reduced antenatal attendance in southern Malawi. Trop Med Int Health. 2009;14:183-9.

48. Chinbuah MA, Adjuik M, Cobelens F, Koram KA, Abbey M, Gyapong M, et al. Impact of treating young children with antimalarials with or without antibiotics on morbidity: a cluster-randomized controlled trial in Ghana. Int Health. 2013:5:228-35.

49. Eriksen J, Mujinja P, Warsame M, Nsimba S, Kouyaté B, Gustafsson LL, et al. Effectiveness of a community intervention on malaria in rural Tanzaniaa randomised controlled trial. African Health Sci. 2010;10:332-40.

50. Ajayi IO, Kale OO, Oladepo O, Bamgboye EA. Using "mother trainers" for malaria control: the Nigerian experience. Int Q Community Health Educ. 2006;27:351-69.

51. WHO. A framework for malaria elimination. Geneva: World Health Organization; 2017. p. 100

52. Kimbi HK, Nkesa SB, Ndamukong-Nyanga JL, Sumbele IUN, Atashili J, Atanga MBS. Socio-demographic factors influencing the ownership and utilization of insecticide-treated bed nets among malaria vulnerable groups in the Buea Health District. Cameroon. BMC Res Notes. 2014;7:624.
53. Michelle C, Stanton A, Bockarie MJ, Kelly-Hope LA. Geographical factors affecting bed net ownership, a tool for the elimination of Anophelestransmitted lymphatic filariasis in hard-to-reach communities. PLoS ONE. 2013;8:e53755.

54. malERA Refresh Consultative panel on Health Systems and Policy Research. malERA: an updated research agenda for health systems and policy research in malaria elimination and eradication. PLoS Med. 2017; 14:e1002454.

55. Moher LA, Tetzlaff J, Altman DG, the PRISMA Group. Preferred reporting items for systematic reviews and meta-analyses. The PRISMA Statement. J Clin Epidemiol. 2009;62:1006-12.

56. Mbonye AK, Bygbjerg I, Magnussen P. Intermittent preventive treatment of malaria in pregnancy: evaluation of a new delivery approach and the policy implications for malaria control in Uganda. Health Policy. 2007;81:228-41.

57. Alonso PL, Lindsay SW, Armstrong JR, Conteh M, Hill AG, David PH, et al. The effect of insecticide-treated bed nets on mortality of Gambian children. Lancet. 1991;337:1499-502.

58. Ndyomugyenyi R, Tukesiga E, Katamanywa J. Intermittent preventive treatment of malaria in pregnancy (IPTp): participation of communitydirected distributors of ivermectin for onchocerciasis improves IPTp access in Ugandan rural communities. Trans R Soc Trop Med Hyg. 2009; 103:1221-8.

59. Kidane G, Morrow RH. Teaching mothers to provide home treatment of malaria in Tigray, Ethiopia: a randomised trial. Lancet. 2000;356:550-5.

\section{Publisher's Note}

Springer Nature remains neutral with regard to jurisdictional claims in published maps and institutional affiliations.
Ready to submit your research? Choose BMC and benefit from:

- fast, convenient online submission

- thorough peer review by experienced researchers in your field

- rapid publication on acceptance

- support for research data, including large and complex data types

- gold Open Access which fosters wider collaboration and increased citations

- maximum visibility for your research: over $100 \mathrm{M}$ website views per year

At BMC, research is always in progress.

Learn more biomedcentral.com/submissions 